\title{
Lateral torsional buckling of glass beams with continuous lateral support
}

\author{
Andreas Luible • Daniel Schärer
}

Received: 25 December 2015 / Accepted: 26 February 2016 / Published online: 24 March 2016

(C) Springer International Publishing Switzerland 2016

\begin{abstract}
There is a growing trend in steel glass facades to maximize the transparency of buildings with structural glass elements e.g. beams, columns, and stiffeners. A relatively new way is the use of glass beams in order to stiffen large glass curtain walls. Although the material glass is a material that is able to resist very high compression stresses, structural glass elements tend to fail because of instability due to their high slenderness. In the past years lateral torsional buckling of glass beams has been studied in many research works. The studies were limited to the fundamental situation of a simple beam without lateral restraint. However, in practice glass beams in glass curtain walls are fixed over the whole length to the front glazing panels by means of structural silicon joints or mechanical fixings. The load carrying behaviour of beams with lateral restraints is different compared to beams with a free lateral displacement. In this work, experimental and theoretical investigations on the lateral torsional buckling of monolithic and laminated glass beams with lateral restraint have been conducted. The objectives were to investigate the load carrying behaviour and to study possible design methods for stability-critical lateral supported glass beams. Finite element simulations were carried out and compared to experimental tests on real size glass beams made of monolithic and laminated glass. The design concept is based on well-known design con-
\end{abstract}

Andreas Luible $(\varangle) \cdot$ Daniel Schärer

Lucerne University of Applied Science and Arts,

Lucerne, Switzerland

e-mail: andreas.luible@hslu.ch cepts using buckling curves and non-dimensional slenderness factors.

Keywords Glass beam · Stability $\cdot$ Lateral torsional buckling · Buckling curves - Lateral restraint

\section{Introduction}

\subsection{General}

There is a growing trend in modern steel glass facades to maximize the transparency of buildings by reducing the dimension of structural elements e.g. beams, columns, and stiffeners. A relatively new way is the use of glass panels as beams in order to stiffen large glass curtain walls (Fig. 1). However, glass, a material that is able to resist very high compression stresses, tends to fail because of instability due to the high slenderness of these elements. In the past years lateral torsional buckling (LTB) of glass beams has been studied in many research works and design concepts have been developed. Most of these studies were limited to the fundamental situation of a simple beam without lateral restraint of the glass edge.

However, in practice glass beams in glass curtain walls are fixed over the whole length to the front glazing panels by means of structural silicon joints or mechanical fixings. The load bearing capacity and also the load carrying behaviour of beams with lateral restraints is different compared to beams with a free lateral dis- 


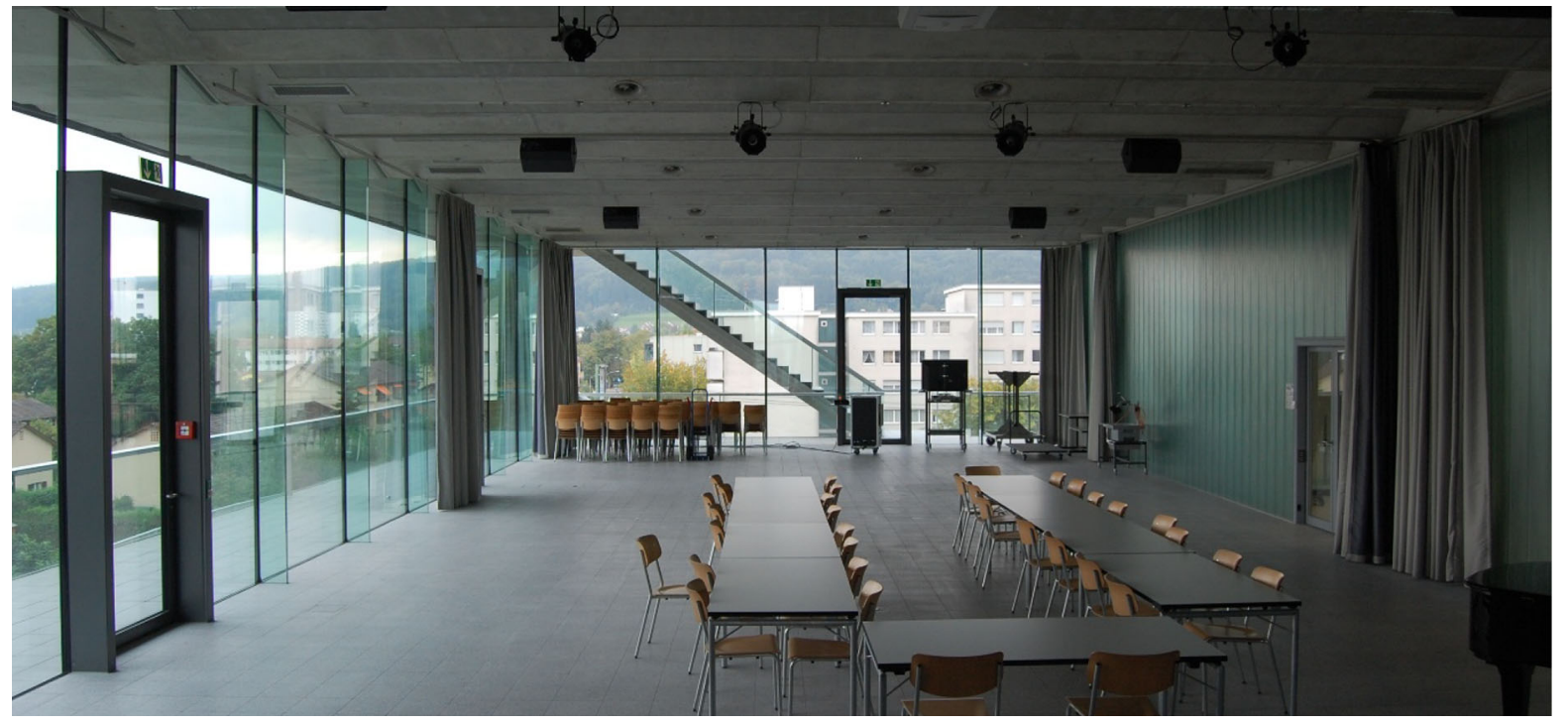

Fig. 1 Glass fins: Leutschenbach school in Zürich. (Gallery 2015)

placement. Currently no design methods exist in order to design buckling critical glass beams with lateral restraint. Consequently glass beams are designed as simply supported beams without lateral restraint and the real load bearing capacity is significantly underestimated.

In a recent research work (Schärer 2015) at the competence centre for façade engineering at Lucerne University of Applied Science and Arts, experimental and theoretical investigations on the LTB of monolithic and laminated glass beams with lateral restraint have been conducted. The objectives of this research were to investigate the load carrying behaviour and to study possible design methods for stability-critical lateral supported glass beams. Numerical simulations were carried out and compared to experimental tests on real size glass beams made of monolithic and laminated glass. Based on these studies a design concept with buckling curves and non-dimensional slenderness factors was developed, which is similar to existing design concepts used in steel construction. The nondimensional slenderness factors can be analytically calculated using a numerical derived function of the first eigenvalue.

\subsection{LTB of glass beams}

LTB buckling of glass beams made of monolithic and laminated glass was studied by (Luible 2004;
Holberndt 2006; Kasper 2005; Belis 2005; Foraboschi 2009; Amadio and Bedon 2010) . All these analytical and experimental studies demonstrated that the load carrying behaviour and also the load bearing capacity not only depends on the geometry, the interlayer shear stiffness and the glass strength but also on geometrical and structural imperfections. The shape and amplitude of geometrical imperfections of structural glass elements were investigated in (Belis et al. 2011). Due to imperfections, such as initial out of straightness, second order effects have a significant influence on the buckling strength of glass beams. Therefore the assessment of the buckling resistance of glass beams by means of a calculation of the elastic critical buckling resistance overestimates the real load bearing capacity and leads to an unsafe design (Fig. 2).

For this reason different approaches have been developed and proposed for the LTB design of glass beams: Analytical models that are able to take into account second order effects exist for fundamental situations but an application in practice is fastidious, especially when laminated glass is used and the interlayer shear interaction is taken into account. A non-linear analysis with an appropriate FE-numerical simulation on the other hand has the advantage that imperfections and different arbitrary boundary conditions may be considered. However, a suitable finite element (FE) simulation requires an appropriate knowledge and reasonable imperfections must be known and applied in 

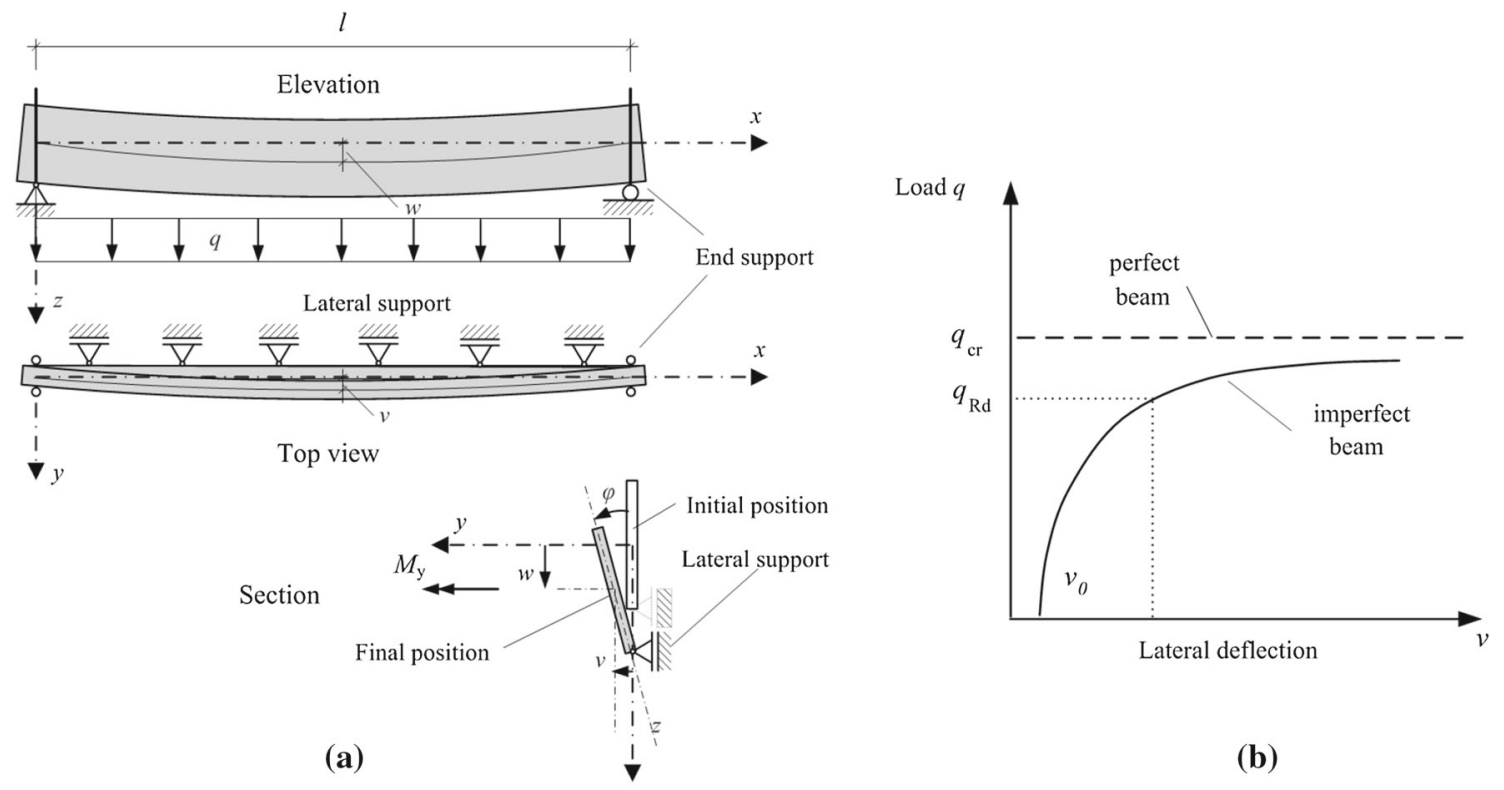

Fig. 2 Lateral supported glass beams (a), typical load carrying behaviour (b)

a right way. In practices, the LTB design approach with buckling curves seems to be the most promising design method. The biggest advantage of the buckling curve concept in practice is that all parameters having an influence on the non-linear behaviour of stability critical structural members, such as geometrical and material imperfections may directly be implemented. Similar to steel construction, where the design of stability critical structural elements with buckling curves is straight forward, it was shown that this approach may also be applied to structural glass members (Luible 2004; Haldimann et al. 2008). However due the different material property and the different origin and amplitude of initial imperfections these design curves cannot be directly applied to glass.

The load carrying behaviour of laminated glass beams with the time and temperature dependant influence of the interlayer stiffness was investigated by (Luible 2004; Kasper 2005; Belis 2005) . It was demonstrated that the shear interaction between interlayer material and glass results in significantly higher load bearing capacity of glass beams. (Challamel and Grihammar 2012)studied the influence of the shear stiffness and in (Belis et al. 2013) the influence of mechanical and geometrical properties on the LTB behaviour of laminated glass beams by means of experimental tests and numerical simulations. Different existing ana- lytical calculation models were compared to numerical simulations and results of several test series by (Bedon et al. 2014). All these studies are limited to the fundamental situation of glass beams, which are laterally not fixed along the edge to e.g. the front glazing of the façade. In practice, especially when glass beams are applied in frameless glass facades, the glass beams are connected to the front glazing by mechanical fixings, like clamps, or glued with structural silicone. The effect of continuous elastic sealant joints on the LTB behaviour of glass beam was assessed in a theoretical research in (Bedon et al. 2015). Based on previous research work and parametric FE simulations, analytical solutions are suggested for the estimation of the elastic critical buckling moment of monolithic glass beams under various loading conditions. By means of a nonlinear FE analyses, the global LTB response was investigated, to assess the sensitivity to initial geometrical imperfections as well as the LTB failure mechanism. Finally, a buckling design curve based on numerical simulations was established, which accounts for the structural contribution provided by structural silicone joints.

\subsection{Objectives and methodology}

The objective of the study (Schärer 2015) was the development of a simple design method in order to pro- 
vide structural engineers in practice a safe and economic design of glass beams with lateral restraints. As demonstrated in previous works (Luible 2004; Bedon et al. 2015) a design approach based on buckling design curves, a common design practice in structural steel design, may also be applied for glass. However, due to different material behaviour and also imperfections, which have a significant influence on the load bearing capacity, steel buckling curves may not be directly applied for structural glass elements. Therefore, the shape of the buckling curve and also the definition of the non-dimensional slenderness are different for glass. The main objectives of the work (Schärer 2015) were:

- the development of a simple analytical and numerical FE model, which is able to describe the load carrying behaviour of laterally restraint glass beams,

- the theoretical study of the LTB behaviour of monolithic and laminated glass beams by means of simple analytical models and numerical FE models,

- the experimental study of the LTB behaviour of monolithic and laminated glass beam with lateral restraints along one edge on real size glass beams,

- the definition of a suitable design buckling curve for glass beams based on parametric studies which were carried out on the developed numerical FE model.

For the determination of the non-dimensional slenderness, which is the basis for the design approach with design buckling curves, the elastic critical buckling moment or the corresponding elastic critical buckling load must be known. The critical buckling load may either be calculated with a numerical FE model or with suitable analytical models. Compared to numerical models, analytical models have the advantage that no FE software is required and the calculation may be carried out much quicker. For glass beams without lateral restraint models exist. For glass beams with lateral restraint a suitable model was developed in the present work. The analytical model, in order to calculate the critical buckling load, is based on the principle of virtual work using the eigenform of the glass beam as the virtual deformation of the beam. For this reason the shape of the eigenform of lateral restraint glass beams was studied in a first step by means of a numerical FE model with the computer software (ANSYS
2014). The objective was the definition of a simple analytical function, which is able to sufficiently approximate the real eigenform shape and, which can then be applied for the calculation of the critical buckling moment of the glass beam. In parallel a detailed numerical FE model was developed, which enables to study the real load carrying behaviour of laterally restraint monolithic and laminated glass beams and to calculate the elastic critical buckling load. For this reason, the model was also applied to compare the elastic critical buckling loads, calculated with the simplified analytical model, with the numerical results. Experimental buckling tests on real size monolithic and laminated glass beams were then carried out in order to compare the real load carrying behaviour comprising all influences, such as friction effects, time and temperature dependant shear stiffness of the interlayer, with the numerical model. Numerous parametric studies were then carried out with the detailed non-linear numerical FE model. The results have been evaluated and a buckling curve for the design of lateral restraint glass beams was proposed. The parametric studies are based on imperfections, which take into account not only the geometrical imperfection of the glass member itself, but also imperfections resulting from installation. Additional lateral loads, such as wind loads acting on the lateral surface of the glass beam in outside applications, were not part of the study. The design curve in this work is limited to a constant load, acting on the lateral restrained glass edge. For simplification reasons, the lateral restraint in this work was assumed as fully rigid and does not allow any lateral displacement. The rotation around the glass edge is assumed to be free without any friction.

A typical connection between a glass fin and a double glazed unit is shown in Fig. 3. In this example a stainless steel profile provided with a special glass holder profile is glued onto the glass fin. The double glazed units are connected to the stainless steel U-profile with local mechanical clamps, which are screwed onto a stainless steel shroud with integrated aluminium screw channel. The clamps are hidden in the edge sealing of the double glazed unit and work as a lateral support for the glass fin. An advantage of this construction is that the structural silicone joint with the glass fin may be prefabricated in the shop and quality critical silicon joints do not have to be carried out on site. The installation of the system on site is similar to widely used stick systems. 
Fig. 3 Typical glass fin connection with a double glazed unit

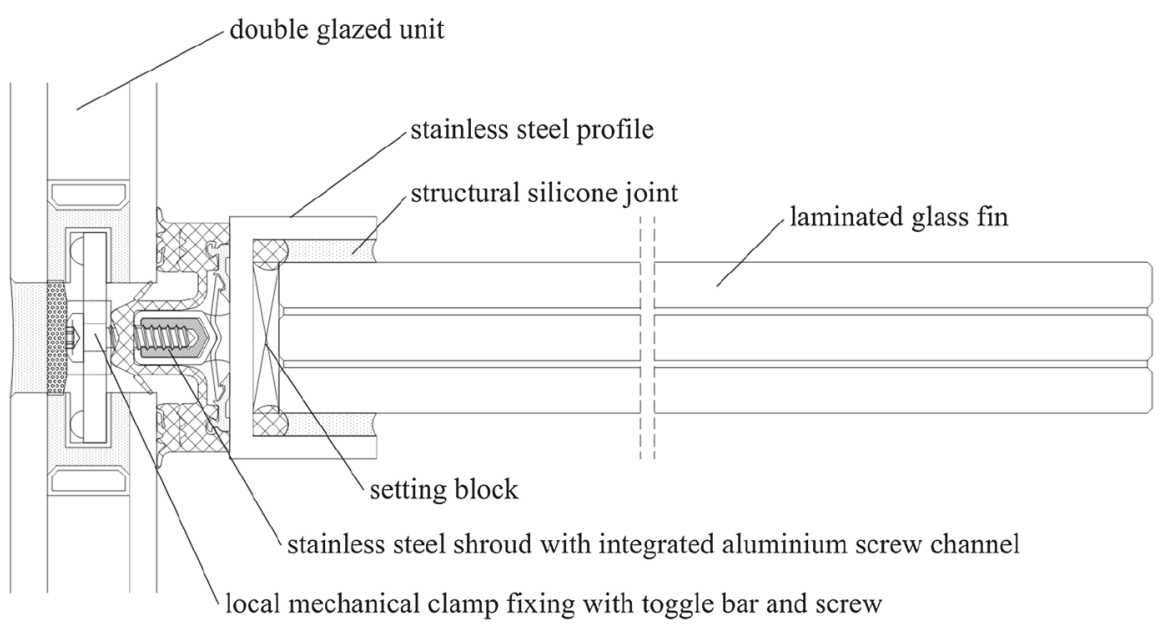

\section{Elastic critical buckling moment}

\subsection{General}

The critical buckling load of laterally restraint glass beams has already been investigated in the past. In (Bedon et al. 2015) a state of the art overview and an analytical approach is presented to determine the elastic critical buckling load of laterally restraint beams. The approach is based on research works carried out in the field of steel construction and which was adapted to glass. The analytical model is able to take into account an elastic connection due to the silicon joint between glass beam and the attached front glazing.

In the present work an analytical model was developed, which is able to determine the elastic critical buckling load of monolithic and laminated glass beams with lateral restraints. The model is developed on the basis of the principle of virtual work (PVW). The application of the PVW method for the assessment of the elastic critical buckling of structural members is straightforward as long as the shape of the buckled member is known and as long as the shape may be described by a mathematical function. For fundamental structural elements, such as simply supported columns, the shape (half-sin) is quite obvious. However, for laterally restraint glass beams, which show a rather three dimensional geometry in the buckled state, the shape is more complex. For this reason a detailed parametric study of the eigenform was first carried out in order to establish a simple relation between geometry, applied load and the shape of the buckled glass beam. The results of the parametric study then allowed establishing an empirical analytical function, which is suitable to describe the shape of the buckled glass beam.

\subsection{Parametric study of the eigenform}

The study was carried out on numerical FE models representing a laterally supported simple beam made of monolithic and laminated glass acc. Figure 2. The glass beam was subjected to a uniformly applied force applied at the bottom glass edge. For each glass beam the eigenvalue, which corresponds to the elastic critical buckling load $q_{c r}$, and the eigenform was determined and analysed. The analysis started with a linear elastic analysis in order to get the stress distribution in the beam, followed by linear bifurcation analysis. All parameters within their range considered in the analysis are shown in Table 1.

The study was first carried out on full models of the glass beams with typical dimensions in order to evaluate the first four eigenvalues and to determine the corresponding eigenform shapes Fig. 4. As expected, for the given system and within the considered range of parameters, the smallest elastic critical buckling load $q_{c r}$ corresponds to the first eigenvalue (Table 2). Generally, the first eigenform corresponds to the most critical shape of the geometrical imperfection, which needs to be considered for the development of a LTB design concept for glass beams. For the studied system, the first eigenform was characterized by one single half sine wave. Because of the symmetric shape of the first eigenform, the model was then reduced to a half model and all further investigations have been performed on 
Table 1 Parametric study of the eigenform

\begin{tabular}{lll}
\hline Parameter & Monolithic glass & $\begin{array}{l}\text { Laminated glass } \\
(2 \text { and 3 glass layer })\end{array}$ \\
\hline Length (mm) & $200-30,000$ & $200-8000$ \\
Height (mm) & $50-500$ & $50-500$ \\
Thickness (mm) & $4,12,19$ & $4,12,19$ \\
Ratio: length/height & $1-60$ & $1-60$ \\
Interlayer thickness (mm) & - & 1.52 \\
Young's modulus interlayer (MPa) & & $0.1-2000$ \\
Number of simulations & 400 & 400 \\
\hline
\end{tabular}

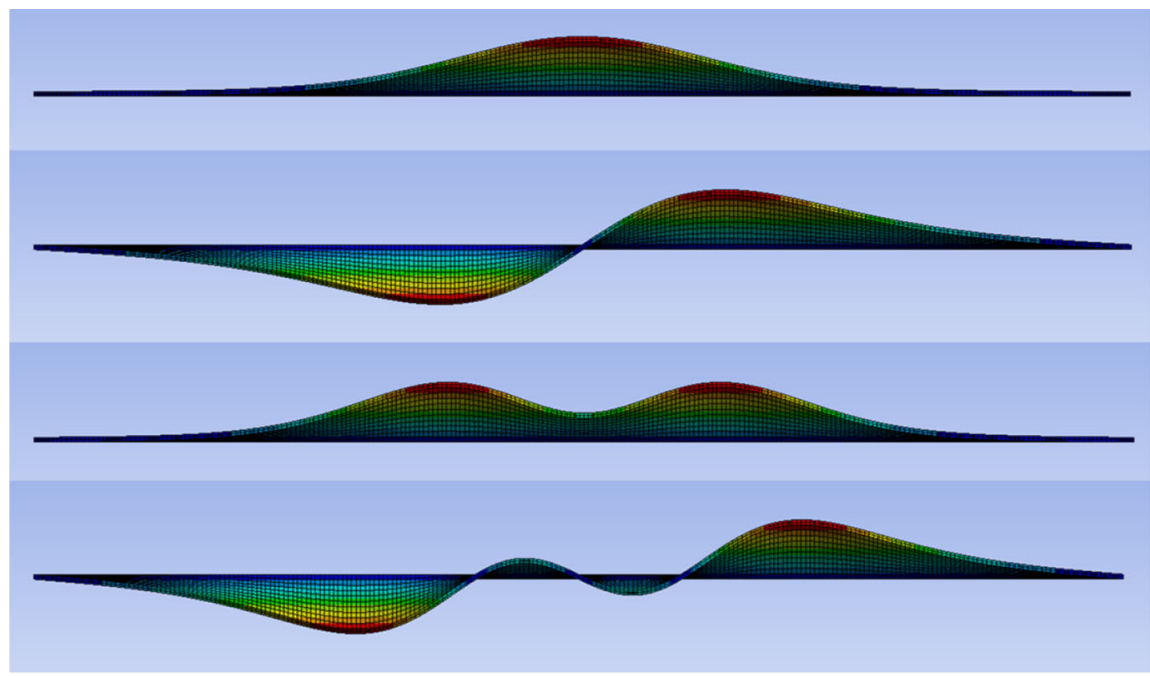

Fig. 4 Eigenform geometry of a laterally restrained glass beam (view from top): $\mathrm{EF} 1$ (top) to EF4 (bottom)

Table 2 Critical buckling load for the first four eigenform shapes (EF1 to EF4): beam length $6000 \mathrm{~mm}$; beam height $300 \mathrm{~mm}$; thickness $12 \mathrm{~mm}$ (mono) and 12/1.52/12 mm (lam.); EPVB $1.0 \mathrm{MPa}$

\begin{tabular}{lllll}
\hline & \multicolumn{2}{l}{ Monolithic glass } & \multicolumn{2}{c}{ Laminated glass (2 glass layers) } \\
\cline { 2 - 4 } & $\mathrm{q}_{\mathrm{cr}, \mathrm{i}}[\mathrm{kN} / \mathrm{m}]$ & $\mathrm{q}_{\mathrm{cr}, \mathrm{i}} / \mathrm{q}_{\mathrm{cr}, \mathrm{EF} 1}[\%]$ & $\mathrm{q}_{\mathrm{cr}, \mathrm{i}}[\mathrm{kN} / \mathrm{m}]$ & 8.9 \\
\hline Eigenform 1 (EF1) & 4.1 & 100 & 9.1 & 100 \\
Eigenform 2 (EF2) & 4.2 & 102 & 10.6 & 119 \\
Eigenform 3 (EF3) & 5.0 & 122 & 10.8 & 121 \\
Eigenform 4 (EF4) & 5.1 & 124 & & 102 \\
\hline
\end{tabular}

the simplified model. It is important to notice that for other structural systems, other load distributions and different support conditions the first eigenvalue and elastic critical buckling load may correspond to a different shape. In (Schärer 2015) also the influence of different interlayer stiffness on the eigenform has been studied. It turned out that the interlayer stiffness has only a slight influence on the eigenform as the shapes are almost identical. However a higher interlayer shear stiffness results in significantly higher critical buckling load.

The resulting shapes of all eigenforms were then evaluated and compared in a non-dimensional diagram. The beam length is indicated on the horizontal axis and the lateral displacement at the beam axis $v$ with the amplitude 1 is indicated on the vertical axis (Fig. 5). 
Fig. 5 Lateral displacement of the eigenform for different glass thicknesses and $\mathrm{l} / \mathrm{h}$ ratios

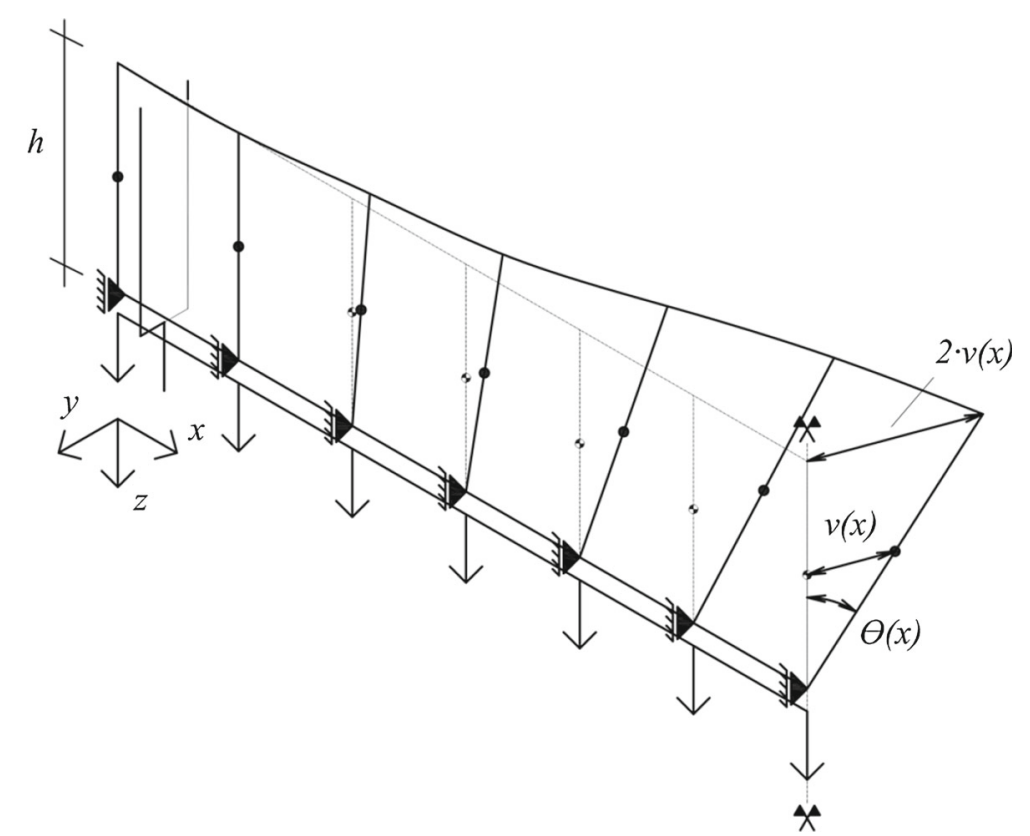

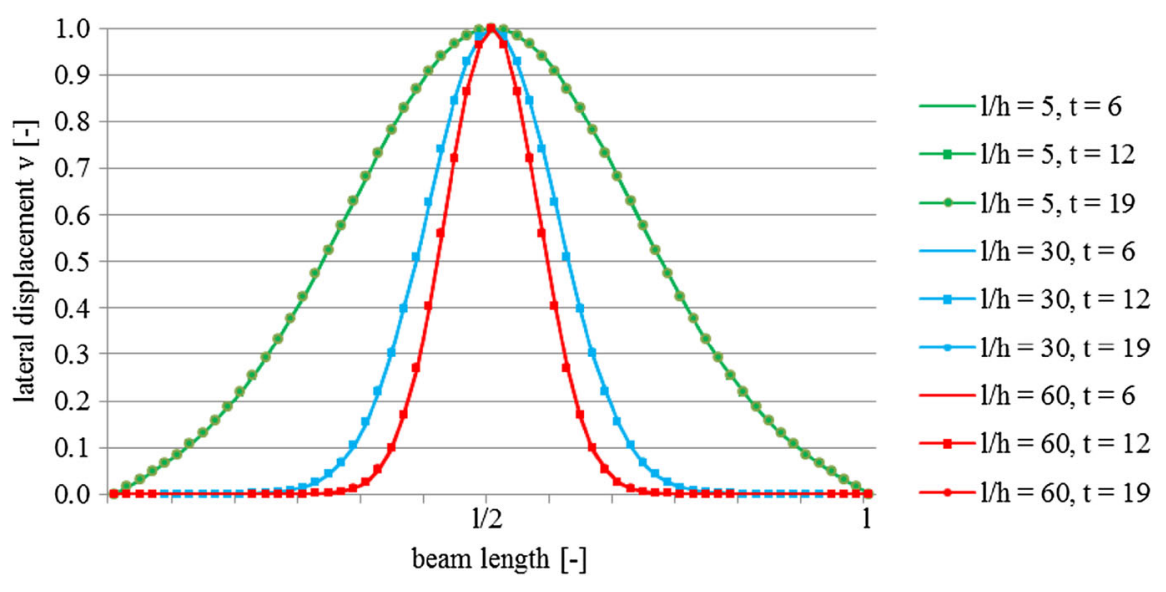

Fig. 6 Simplified relation between lateral displacement and torsional rotation of a laterally restraint glass beam (half model)
It can be seen in the diagram that the eigenform shape of monolithic glass beams with lateral restraints solely depends on the ratio between beam length $l$ and beam height $h$. The glass thickness has no influence on the shape of the eigenform. Beams with small $l / h$ ratios are characterized by a lateral deformation, which spans over the entire glass edge. On the other hand, beams with higher $l / h$ ratios show only a local lateral displacement, which is concentrated at the beam centre. Eigenforms of beams with identical $l / h$ ratios are almost identical. The same conclusion could be drawn for laminated glass: the shear stiffness of the interlayer material has only a marginal influence on the eigen- form of the beam and the eigenform mainly depends on the $l / h$ ratio (Schärer 2015).

The lateral displacement $v$ of the beam axis, obtained by the 800 simulated beams, were then analysed in detail. The objective was to find a mathematical correlation between the $l / h$ ratio and the lateral displacement, which then enables to describe the eigenform of the glass beam by a simple mathematical function. This mathematical formulation can then be applied with the PVW method in order analytically calculate the elastic critical buckling load of a laterally restraint glass beam. Figure 6 explains the correlation between the lateral displacement at the beam aixs $v(x)$, the lateral 
Fig. 7 Eigenform geometry (lateral displacement at the centre of the beam axis): comparison between FE model and simplified approximation

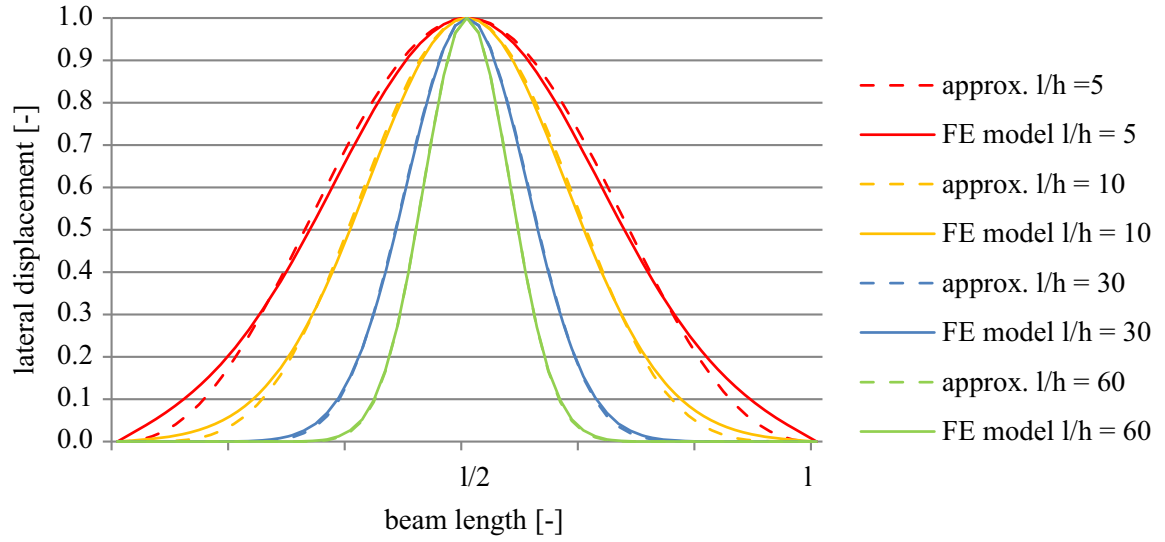

displacement at the top edge $2 v(x)$ and the rotation of the beam axis $\theta(x)$. The latter is defined by $v(x)$ and the height $h / 2$. In (Schärer 2015) two different approaches were discussed, whereas the definition according Eq. (1) appears to be the most appropriate. The formulation of $v(x)$ in this approach requires the definition of a so called critical length $l_{c r, L T}$, a fictive length, which is a function of the $l / h$ ratio of the beam. With this formula the laterally displacement $v(x)$ and the rotation $\theta(x)$ of laterally restraint glass beams may be approximately described.

$$
\begin{aligned}
& v(x)=A \cdot \sin \left(\frac{\pi x}{l_{c r, L T}}\right) \\
& l_{c r, L T}=\varphi \cdot l \\
& \varphi(x)=0.79 \cdot \alpha^{-0.54} \\
& \alpha=\frac{l}{h} \\
& \theta(x)=\frac{2 \cdot v(x)}{h}
\end{aligned}
$$

In Fig. 7 the correlation of the lateral displacement at the beam axis $v(x)$ between numerical results and the approximated function is shown for different $l / h$ ratios. The diagram demonstrates that especially for $l / h$ ratios between 8 and 25, which are typical ratios of glass beams in practice, the correlation between numerical results and the approximated function is good.

\subsection{Elastic critical buckling moment calculated with the PVW}

Thanks to the simplified shape function of the lateral displacement $v(x)$ and the beam rotation $\theta(x)$, the elastic critical buckling load of laterally restraint glass beams $q_{c r}$ may be determined with the principle of virtual work (PVW). The functions, which are developed in the previous section, are applied as virtual displacements for the calculation of the internal and external work. The bending moment $M_{y}(x)$ about the strong axis of the beam is defined as:

$M_{y}(x)=\frac{1}{2} q_{z}\left(x \cdot l-x^{2}\right)$

The deformation in z-direction, due to the applied external uniformly distributed load $q$ is assumed to be zero. Therefore, also the resulting external work $\delta W_{\text {ext }}^{I}$ due to the applied load $q$ becomes zero.

$\delta W_{e x t}^{I}=0$

The external work $\delta W_{\text {ext }}^{I I}$ results from second order effects, which are caused by the external load $q$ and the rotation of the beam cross section $\theta(x)$. Due the beam rotation in the deformed position the applied load deviates from the shear centre and thus the load eccentricity causes an external work.

$\delta W_{\text {ext }}^{I I}=-\int_{0}^{l}\left(q_{z} \cdot z_{q} \cdot \delta \theta(x) \cdot \theta(x)\right) d x$

The inner work $\delta W_{i n t}^{I}$ due to first order effects is caused by the lateral deformation and the rotation of the beam cross section.

$$
\begin{aligned}
\delta W_{i n t}^{I}= & -\int_{0}^{l}\left(E I_{z} \cdot \delta v^{\prime \prime}(x) \cdot v^{\prime \prime}(x)\right. \\
& \left.+G J_{T} \cdot \delta \theta^{\prime}(x) \cdot \theta^{\prime}(x)\right) d x
\end{aligned}
$$


The inner work $\delta W_{i n t}^{\mathrm{II}}$ results from inner forces due to second order effects multiplied with the lateral deformation and the rotation of the beam cross section. Whereas the bending moment about the weak axis $M_{z}(x)$ is determined with the product of bending moment about the strong axis $M_{y}(x)$ and rotational deformation of the beam axis $\theta(x)$.

$$
\begin{aligned}
\delta W_{i n t}^{I I}= & -\int_{0}^{l}\left(M_{y}(x) \cdot \delta v^{\prime \prime}(x) \cdot \theta(x)\right. \\
& \left.+M_{y}(x) \cdot \delta \theta(x) \cdot v^{\prime \prime}(x)\right) d x
\end{aligned}
$$

The total sum of external and internal work is then:

$$
\delta W_{t o t}=\sum\left(\delta W_{e x t}^{I}+\delta W_{e x t}^{I I}+\delta W_{i n t}^{I}+\delta W_{i n t}^{I I}\right)
$$

As the total resulting stiffness has only one degree of freedom, the matrix has the dimension of $\mathrm{n} \cdot \mathrm{m}=1$. After partial derivation with respect to real and virtual deformations the determinant is set to zero. This results in one single unknown parameter, the load $q_{z}$. The determined load $q_{z}$ corresponds to the critical lateral torsional buckling load $q_{c r}$.

$M=\left[\frac{d}{d A}\left(\frac{d}{d \delta A} \delta W_{t o t}\right)\right] \rightarrow|M| \stackrel{!}{=} 0 \rightarrow q_{c r}$

With the critical lateral torsional buckling load $q_{c r}$, the critical buckling moment $M_{c r, L T}$ may be calculated. Due to the approximated reduced length $l_{c r, L T}$, the bending moment $M_{y, \mathrm{cr}}(\mathrm{x})$ around the strong axis has to be adapted to:

$$
\begin{aligned}
M_{y, c r}(x)= & \frac{1}{2} q_{c r}\left(\left(x+\frac{1}{2}\left(l-l_{c r, L T}\right)\right) l\right. \\
& \left.-\left(x+\frac{1}{2}\left(l-l_{c r, L T}\right)\right)^{2}\right)
\end{aligned}
$$

The presented approach with an approximated deformation function in order to determine the elastic critical buckling load of lateral restraint glass beams may be applied to monolithic and laminated glass cross section. However, the shear interaction between interlayer and glass in case of laminated glass has a significant influence on the torsional stiffness and as a consequence also on the buckling behaviour and the elastic critical buckling moment $M_{c r, L T}$. The bending stiffness $E I_{z}$ and the torsional stiffness $G J_{T}$ of a laminated glass cross section, taking into account the shear interaction, is higher. However, the increase in stiffness depends on the shear stiffness of the interlayer material. Typical interlayer materials show a strong temperature and time dependant shear stiffness. Therefore, in common applications in practice shear interaction effects may range from "no shear interaction effect" to "full shear interaction", whereas the latter corresponds to a monolithic cross section with the thickness of the laminated glass package. For structural calculations the bending stiffness $E I_{z}$ and the torsional stiffness $G J_{T}$ of laminated glass cross section may then be replaced by an equivalent bending $E I_{z, \text { eff }}$ and torsional stiffness $G J_{T, e f f}$ based on an equivalent thicknesses for bending and torsion.

In many research works different mechanical models have been developed in order to determine the bending and torsional stiffness of sandwich cross sections such as laminated glass (Challamel and Grihammar 2012; Kasper 2005). In this work the equivalent bending $E I_{z, \text { eff }}$ and torsional stiffness $G J_{T, \text { eff }}$ was calculated according the sandwich model developed in (Stamm and Witte 1974).

\subsection{Comparison with the numerical model}

The analytical model, presented in the previous paragraph, to determine the elastic critical buckling moment of laterally restraint glass beams was compared to the numerical model which was used for the study of the eigenform in paragraph 2.2. The comparison was carried out for different glass beam geometries with a length $3000 \mathrm{~mm} \leq l \leq 9000 \mathrm{~mm}$ a height of $50 \mathrm{~mm} \leq$ $h \leq 1800 \mathrm{~mm}$ and a thickness of $6 \mathrm{~mm} \leq t \leq 19 \mathrm{~mm}$. The $l / h$ ratio varied from 5 to 60 . The results for monolithic glass are displayed in Fig. 8, whereas the analytically calculated elastic critical buckling load $q_{c r, \text { analytical }}$ is compared to the numerically calculated elastic critical buckling load $q_{c r, F E}$ as a function of the ratio $l / h$ on the $x$-axis. The deviation between the analytically and numerically calculated critical buckling load $q_{c r}$ is in the range between 97 and $103 \%$. It can be noticed that the analytical approach over- or underestimated the numerically calculated buckling load by maximum $2.6 \%$. The highest deviation occurs for beam geometries with a ratio $l / h \leq 5$ and $l / h \geq 60$. The difference for geometries $l / h \leq 5$ is because the load carrying behaviour deviates from beam theory and the 


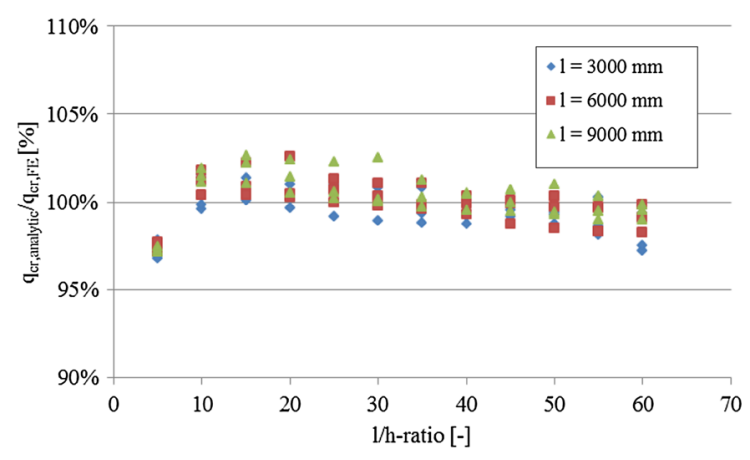

Fig. 8 Comparison of critical buckling load $q_{c r}$ calculated with analytical and numerical model

influence of membrane stiffening effects are getting significant.

However in the typical range of practical applications with $10 \leq l / h \leq 20$ the analytical model overestimates the critical buckling load of laterally restraint glass beams by maximum $3 \%$. The non-dimensional slenderness of a beam is defined as:

$\bar{\lambda}_{L T}=\sqrt{\frac{M_{R k, y}}{M_{c r, L T}}}=\sqrt{\frac{q_{R k, y}}{q_{c r, L T}}}$

with the characteristic strength of the beam in bending $M_{R k, y}$ and the elastic critical lateral torsional buckling moment $M_{c r, L T}$. This means, a calculation of the slenderness of monolithic glass beams with the simplified analytical approach leads to an overestimation of maximum $(2.6 \%)^{1 / 2}=1.6 \%$.

The same investigations were made with laminated glass beams with two glass layers. The comparison was carried out for glass beam geometries with a length $4000 \mathrm{~mm} \leq l \leq 8000 \mathrm{~mm}$ a beam height of $150 \mathrm{~mm} \leq$ $h \leq 450 \mathrm{~mm}$ and a glass thickness of $6 \mathrm{~mm} \leq t \leq$ $19 \mathrm{~mm}$. The interlayer thickness $t_{\text {int }}$ was $1.52 \mathrm{~mm}$ with a shear stiffness $0.1 \mathrm{~N} / \mathrm{mm}^{2} \leq E_{\text {int }} \leq 100 \mathrm{~N} / \mathrm{mm}^{2}$. The $l / h$ ratio varied from 9 to 53 . The analytically calculated elastic critical buckling load $q_{c r}$,analytical was compared to the numerically calculated elastic critical buckling load $q_{c r, F E}$, whereas the deviation between the analytically and numerically calculated critical buckling load $q_{c r}$ is between 97 and $109 \%$. Therefore, a calculation of the slenderness of laminated glass beams with the simplified analytical approach leads to an underestimation of $(3 \%)^{1 / 2}=1.7 \%$ and overestimation of the slenderness of $(9 \%)^{1 / 2}=3.0 \%$.

\section{Numerical simulation}

The FE model, which was initially developed for the study of the eigenform, was further elaborated, in order to study the non-linear buckling behaviour of glass beams with lateral restraints comprising initial imperfections (Fig. 9). The model was created with the FE software (ANSYS 2014) with solid elements. Preliminary studies with different mesh sizes were carried out in order to find an optimal mesh size with respect to the quality of the results and computation time. Finally a mesh was applied with one element per layer through the thickness of the beam. The element size along the beam was varied in such a way that the results converged with a difference of less than $1 \%$. The beam was laterally restraint at the bottom edge and the vertical edges by stiff lateral supports. All supports allowed a free rotation of the edge. The load was applied at the bottom edge of the beam. Due to symmetrical boundary conditions and symmetrically applied loads, only a half model of the glass beam was used in order reduce computational cost.

The numerical FE calculation was carried out in a multi-step analysis as described in (Luible 2004) and (Haldimann et al. 2008):

- Creating the model with appropriate elements, mesh size and material definition.

- Application of the boundary conditions such as vertical and lateral supports and loads. In case of laminated glass, applied conditions have to allow for free rotation and shear deformation of the glass.

- Start of the simulation with a modal analysis of the system. The resulting eigenvalue corresponds to the critical buckling load, the resulting first eigenvector corresponds to the first critical buckling shape of the initial deformation.

- Application of an initial deformation using a scaled shape of the first eigenform of the system. The amplitude of the deformed shape represents the total imperfection of the glass beam.

- Non-linear incremental structural analysis on this 'imperfect' system.

- Post-processing in order to identify the maximum deflection and principal surface stress.

An ideal elastic material behaviour was assumed for glass and the interlayer material. In reality, interlayer materials show a visco-elastic time- and temperature dependent behaviour. The material behaviour of inter- 

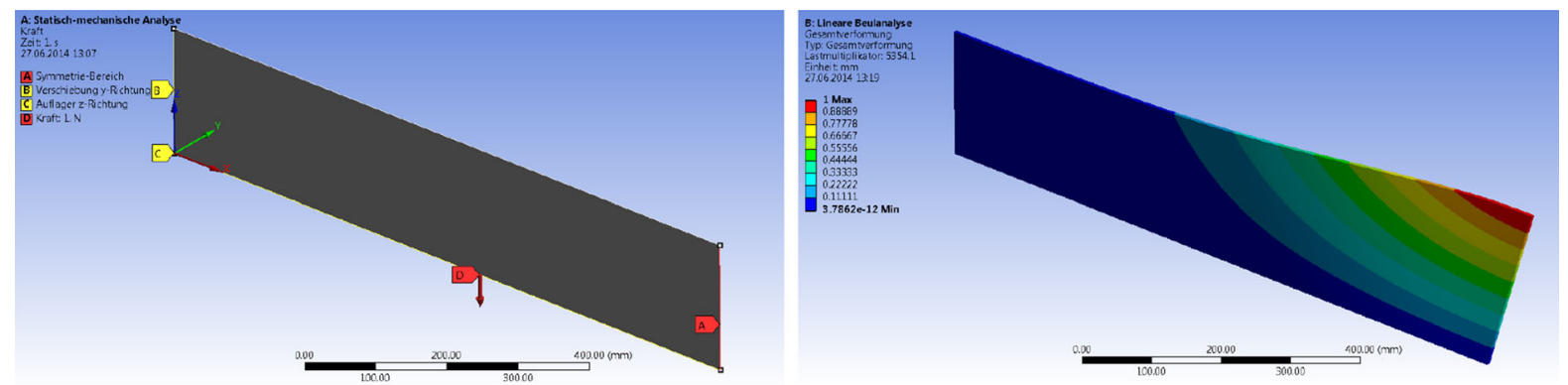

Fig. 9 Numerical FE model (ANSYS 2014): FE half model (left), FE model after eigenvalue analysis (right)

layer materials was studied in many research works and simplified material models, which allow determining an equivalent shear stiffness for a given temperature and load duration. Based on these simplified material models, on manufacturers material specifications and own experimental studies, the equivalent interlayer shear stiffness was determined for the non-linear FE analysis.

A comparison of the numerical FE model with the experimental investigations carried out on monolithic and laminated glass beams is addressed in the next chapter.

\section{Experimental investigation}

\subsection{Test setup}

In order to study the load carrying behaviour of laterally restraint glass beams in reality and in order to validate the developed numerical non-linear FE model, lateral torsional buckling tests on glass beams have been performed in the material test lab at Lucerne University of Applied Science and Arts. The focus of the tests was more on the load carrying behaviour of the glass beams and the influence of initial imperfections on the deflection behaviour. This non-linear load deflection behaviour was then compared to the non-linear FE model results. The tested system corresponds to a simply supported glass beam, which is laterally supported at the bottom glass edge as it is shown in Fig. 2. In contrast to the system in Fig. 2, the load is not applied as a continuous load but as a local concentrated force at half span.

A special test set-up, as shown in Fig. 10 was developed and built for the intended lateral torsional buckling tests. The tested glass beams were installed on a massive steel frame, which enabled an easy installa- tion of the different supports and the pneumatic load introduction device at the bottom. The steel frame was also used to fix the displacement transducers for the monitoring of the lateral beam deflections.

The glass beam was fixed at both extremities by so called fork supports. They support the glass beam in vertical and lateral direction over the beam height but at the same time allows a free rotation of the beam end around the z-axis. The bottom edge of the glass beam was laterally fixed by eight specially machined aluminium supports (Fig. 11a). They allow a free movement in vertical direction, a free rotation around the longitudinal axis of the glass edge, but at the same time prevent a lateral displacement of the glass beam. The lateral supports at the bottom of the glass edge consist of round aluminium peace, which were glued onto the glass beam. L shaped steel profiles on each side of the aluminium pieces hold the glass edge in position and prevent a lateral displacement under loading. PTFE sheets in order to reduce friction have been installed between $\mathrm{L}$ profiles and aluminium pieces. Due to the geometry of the aluminium pieces the rotation axis of the glass beam was $20 \mathrm{~mm}$ below the glass edge. The numerical models, which were used for the comparison, have been adapted accordingly. The load was incrementally applied as a concentrated force at half span of the beam with a special device. A U-shaped steel flat with a pinned connection to the steel bar, which was fixed to the pneumatic cylinder at the bottom, was glued onto the glass beams (Fig. 11b). The axis of the pinned connection was also at $20 \mathrm{~mm}$ distance from the glass edge similar to the lateral supports. Before the glue was applied, the centred position of the steel piece could be adjusted with the help of distance screws.

During the tests, the applied force was measured and recorded by a load cell, which was placed between 


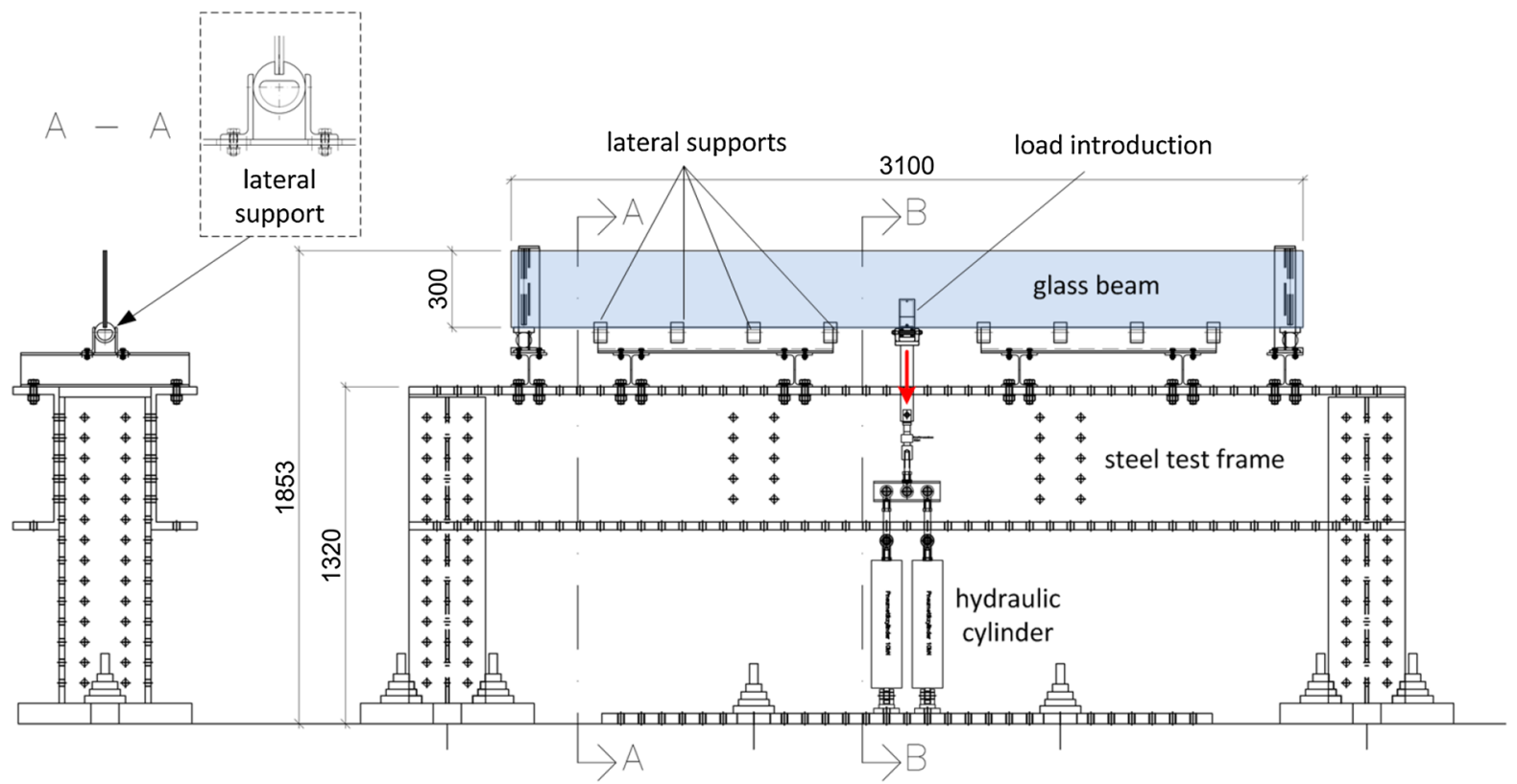

Fig. 10 Test set up for the lateral torsional buckling tests

Fig. 11 Lateral glass restraints (a) and load introduction device (b)

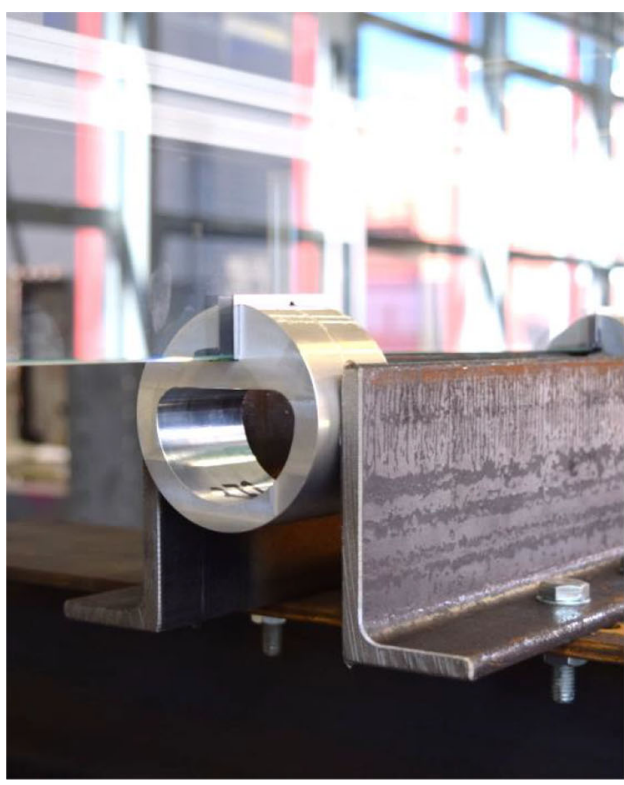

(a)

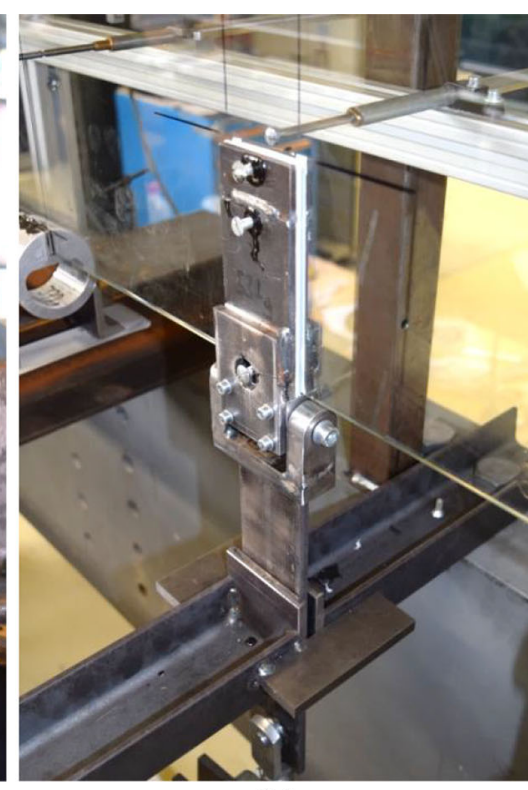

(b) pneumatic cylinder and steel flat. The lateral deflection of the glass beam was measured with displacement transducers at the centre of the beam and at nine locations: at the position of the load application and above each of the eight lateral supports (Fig. 11b). Also the vertical beam displacement was measured at the top edge of the beam.
The geometry and number of the test specimens is summarized in Table 3. In total three monolithic glass beams and four laminated glass beams have been tested. In Fig. 12 a typical deformed laterally supported glass beam after buckling is shown. It can be seen that the lateral displacement of the top glass edge exceeds the thickness of the glass. 
Table 3 Geometry of all tested glass beam

\begin{tabular}{lll}
\hline Parameter & Monolithic glass & Laminated glass (2 glass layer) \\
\hline Length $(\mathrm{mm})$ & 3100 & 3100 \\
Height $(\mathrm{mm})$ & 300 & 300 \\
Thickness $(\mathrm{mm})$ & $1 \times 6 ; 2 \times 8$ & 6 \\
Ratio: length/height & 10 & 10 \\
Interlayer thickness $(\mathrm{mm})$ & - & 1.52 \\
Interlayer & - & Saflex RB 41/EVASAFE G77 \\
Number of tests & 3 & 4 \\
\hline
\end{tabular}

Fig. 12 Support, load introduction of the glass beam and buckled glass beam during the test

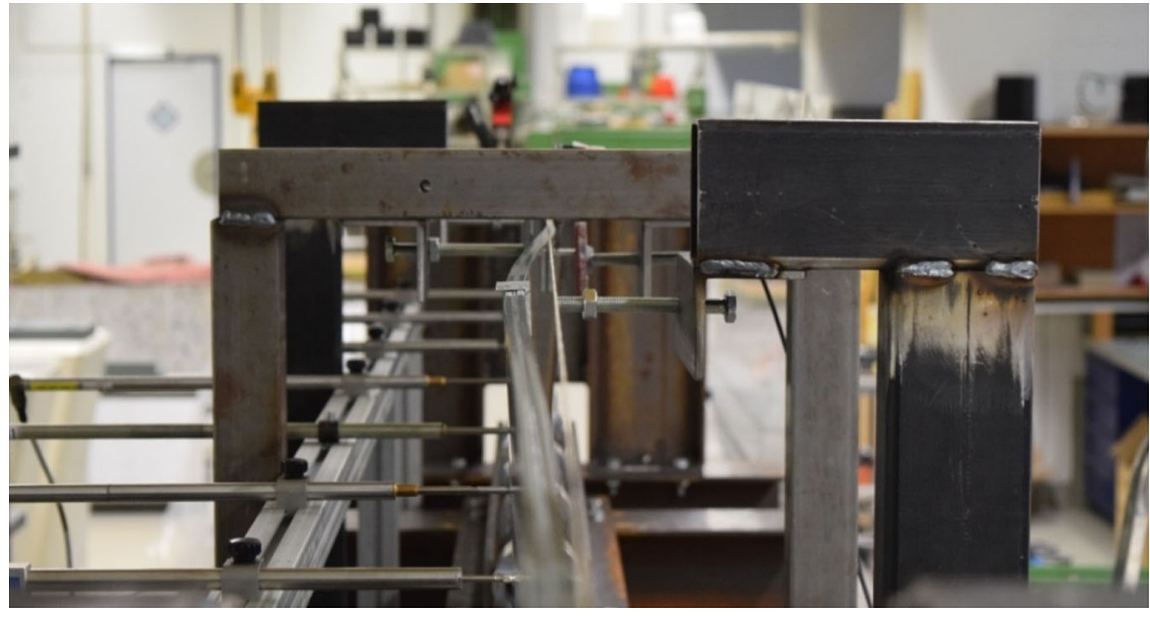

\subsection{Comparison with the numerical model}

The objective of the lateral torsional buckling tests was the investigation of the load carrying behaviour for a comparative study with the numerical FE model. The numerical model has been adapted to the situation of the buckling test. The bottom edge of beam is laterally restraint only locally at nine points and the axis of the pinned connection is located at $20 \mathrm{~mm}$ distance from the glass (Fig. 11). The load in the Fe model was also applied as a concentrated load at half span. The load during the test was not increased up to glass failure. Therefore one glass beam could be used for several tests.

Figure 13 shows the result of lateral torsional buckling tests carried on a $6 \mathrm{~mm}$ and an $8 \mathrm{~mm}$ monolithic glass beam. Each glass beam was tested three times. For both specimens the maximum initial imperfection was determined with $1.9 \mathrm{~mm}$. In both diagrams an initial deviation between numerical FE model and test results can be observed. This is due to friction effects at the supports. Once the laterally deflection starts to develop and the influence of friction becomes less important, the measured lateral deflection of the tested beam approaches quickly the theoretical line resulting from the numerical simulation. It can also be noted that the applied force asymptotically approaches but never exceeds the elastic critical buckling load $F_{c r}$, which was calculated with the numerical model. All three tests, which were carried out on the same specimen show an almost identical load carrying behaviour.

In order to simulate the exact behaviour of tested beam, the amplitude of the initial imperfection of the FE model was set to $1.9 \mathrm{~mm}$. The $1.9 \mathrm{~mm}$ amplitude and the shape correspond to the initial imperfection of the test, whereas $1.0 \mathrm{~mm}$ was the measured initial imperfection of the tested glass beam and $0.9 \mathrm{~mm}$ an additional imperfection due to the test rig, supports, etc.

The critical buckling load was one of the criteria for the chosen geometry of the tested glass beams. The geometry results in critical buckling loads of the first and the second eigenform, which are very close. This 

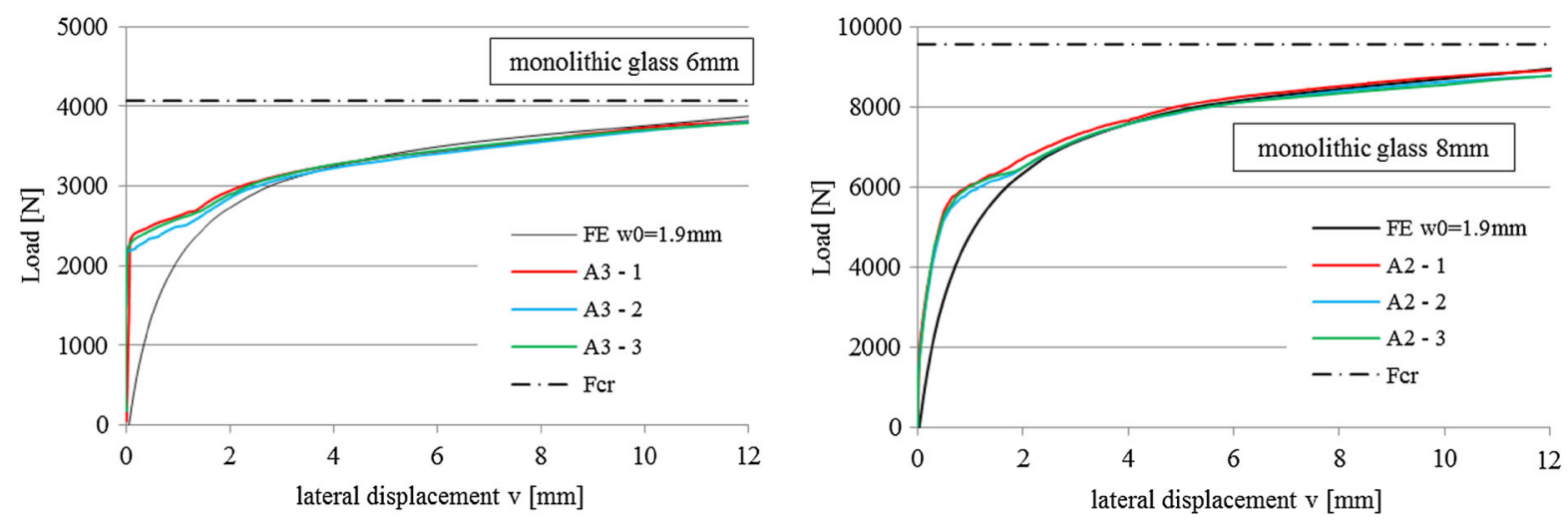

Fig. 13 Comparison between LTB test and numerical simulation: $6 \mathrm{~mm}$ (specimen A3) and $8 \mathrm{~mm}$ (specimen A2) monolithic glass

means, the shape of the beam in its buckled state, either conform to the first eigenform, or conform to the second eigenform, depends strongly on the shape of the initial natural imperfection of the beam. In case the initial imperfection is closer to the first eigenform, the beam buckles in the first eigenform shape. In case the initial imperfection is closer to the second eigenform, the beam starts to buckle in the second eigenform shape.

In the tests, which are shown in Fig. 13, the initial imperfection shape did not correspond to the first eigenform and the measured amplitude of $1.0 \mathrm{~mm}$ was relatively small. As a consequence and as expected, the beam buckled in its second eigenform. However, an important observation during test was that some of the tested beams, which first started to buckle in the second eigenform, suddenly "jumped" back to the shape of the first eigenform. This leads to the important conclusion that even if the initial imperfection does not correspond to first eigenform and even the beam starts to buckle in a shape conform to a higher order eigenform, the beam may suddenly change its deformed shape conform to the first eigenform. Thus a design concept, like design buckling curves, must be developed and based on a critical initial imperfection, which represents a scaled first eigenform.

Due to the time and temperature dependant shear stiffness of the interlayer in laminated glass the load was applied in a different way compared to monolithic glass. A define load was instantaneously applied on the glass beam and the development of the maximum lateral deflection was monitored and recorded over time. With the numerical FE model single deflection results have been calculated, which were based on an equivalent shear modulus for a given load duration and tem-

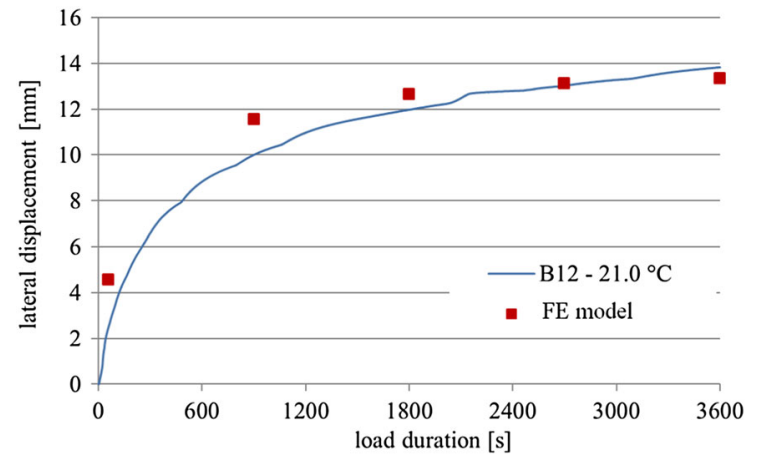

Fig. 14 Typical LTB test with a laminated glass beam with PVB: lateral displacement at beam centre

perature. The applied load for laminated glass beams with PVB interlayer (Saflex RB 41) was $10,000 \mathrm{~N}$ the applied load for laminated beams with EVA interlayer (EVASAFE G77) was 16,000 N.

Figure 14 shows the result of a typical lateral torsional buckling test with lateral restraint compared to the results of the numerical simulation. The correlation between test result and the calculated results (red dots) is good. An equivalent shear modulus for load durations of 60 s, 900 s, 1800 s, 2700 s and 3600 s was applied for the numerical calculations. The maximum initial imperfection of the tested glass beam was 2.5 $\mathrm{mm}$.

All other tests are summarized in (Schärer 2015). The tests with PVB interlayer show a similar and good correlation with the numerical model. Therefore, it can be concluded that the developed numerical model is able to describe the load carrying behaviour of a laminated glass beam subject to lateral torsional buckling. 
However the correlation between the tested laminated glass beams with EVA interlayer and the numerical model was not satisfying. The calculated lateral deformations, based on the shear stiffness values provided by the manufacturer, were much higher than the measured displacements in the tests. It turned out that the provided shear stiffness values for EVA interlayer were to low and further experimental studies in order to get more realistic material data is required.

\section{Design concept}

\subsection{General}

Different design concepts for stability critical structural members of glass are discussed in (Haldimann et al. 2008). The lateral torsional buckling design with design curves, such as those adopted in steel and timber design provide a simple and efficient approach. This approach is also applicable for glass. Buckling curves give reduction factors $\chi_{L T}$ in order to determine the load bearing capacity of stability critical structural elements, as a function of the slenderness ratio $\bar{\lambda}_{L T}$. The slenderness ratio of glass beams was already defined in chapter with Eq. (14), whereas the required characteristic bending strength $M_{R k, y}$ is given by the characteristic strength of the glass beam and the elastic critical buckling moment $M_{c r, L T}$ may be determined with the approach presented in chapter 2 , in (Bedon et al. 2015) or with a suitable numerical FE model.

Buckling design curves are a function of the structural system, the boundary and support conditions, the applied loads (concentrated, continuous, etc.) the glass type and of the imperfections. Buckling design curves for glass beams have been developed for example in (Haldimann et al. 2008) for beams without lateral restraint and in (Bedon et al. 2015) for beams with lateral elastic restraint. In the present research work (Schärer 2015) a buckling design curve for glass beams with a rigid lateral support as shown in Fig. 3 and a continuous constant load (Fig. 2) was developed. The numerical model, which was described in chapter 3 and verified by the experimental tests, was used to generate reduction factors. The buckling design curve was then defined as a lower boundary line of all these generated reduction factors. The non-linear numerical parametric FE simulations were carried out on a wide range of different beam geometries, glass compositions and interlayer shear stiffness values.

\subsection{Assumed initial imperfection}

The non-linear load carrying behaviour strongly depends on the initial imperfection of the glass beams. Therefore the assumption of a realistic and reasonable initial imperfection is important for the non-linear numerical parametric FE simulations, the resulting reduction values and also the quality of the resulting buckling design curve. For the lateral torsional buckling design of glass beams in practice realistic imperfection values should not only comprise the initial geometrical imperfection of the structural glass member resulting from production, they also have to address imperfections due to installation. For this reason three imperfection components have been identified and considered in the subsequent development of the buckling curve:

- $\Delta_{1}$ : imperfection due to an initial rotation (Fig. 15a);

- $\Delta_{2}$ : imperfection due to misalignment from the theoretical axis after installation (Fig. 15b);

- $\Delta_{3}$ : remaining initial imperfection due to production after installation (Fig. 15c).

The initial rotation of the glass beam after installation $\Delta_{1}$ represents a deviation of the structural element after installation in such a way that the angle between the double glazed units is not orthogonal (Fig. 15a). The value of $h / 300$ is common for structural steel members used in steel glass curtain walling. As glass fins typically are supported at both extremities with steel brackets and steel connections this value may also be applied for structural glass beams.

The initial imperfection $\Delta_{2}$ represents a local lateral misalignment from the theoretical axis after installation (Fig. 15b). Referring to the common practice in steel construction, it may be assumed also for glass beams that the axis is not in line with the theoretical axis after the glass beams are installed and fixed to the double glazed units. The value of $5 \mathrm{~mm}$ is a common value used for structural steel members in facades and has been adopted here.

The initial imperfection component $\Delta_{3}$ results from the initial geometrical imperfection after production. The initial out of plane curvature of glass beams after production was studied in (Belis et al. 2011). A maximum value of $l / 400$ was recommended for the lateral 


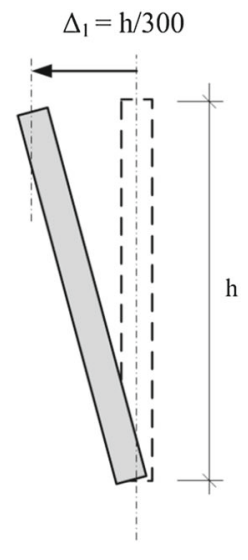

(a)

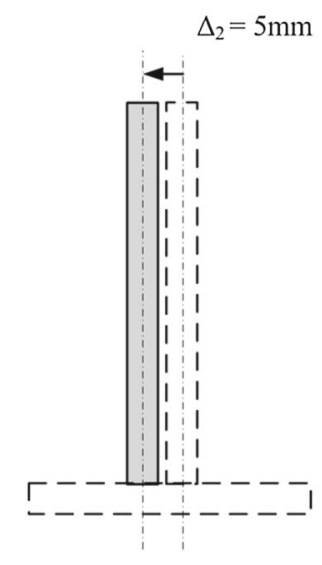

(b)

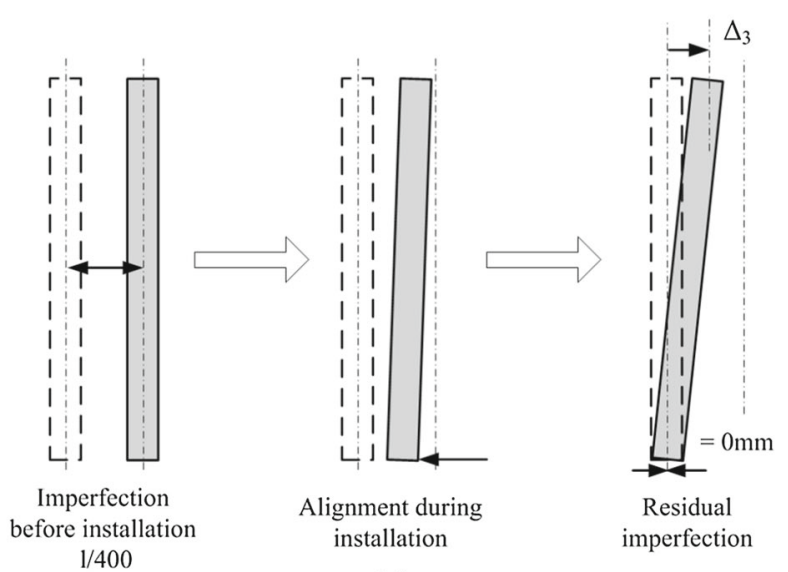

(c)

Fig. 15 Assumed imperfections for laterally restraint glass beam: a initial rotation, b lateral deviation from theoretical axis over the length, $\mathbf{c}$ remaining initial imperfection after installation

torsional buckling design of glass beams. The evaluation of the measured initial deformation was carried on glass beams without lateral restraints. For a $6000 \mathrm{~mm}$ long glass fin this would result in a maximum deviation from the straight axis of the beam of $15 \mathrm{~mm}$. From aesthetical point of view it is questionable if such a misalignment will be accepted in practice. The bending stiffness of the glass beams around the weak axis is small and in practice the glass fins will be aligned during installation in order to meet the architectural requirements. Therefore, in (Schärer 2015) only the remaining out of plane curvature was considered after aligning the glass beam to the theoretical straight axis. A parametric study on the FE model on glass beams with the dimensions used for the development of the buckling design curve was carried out in advance. It turned out that after aligning a maximum remaining out of plane curvature of only $1 \mathrm{~mm}$ is left, which needs to be considered as remaining imperfection.

The total maximum initial imperfection applied for the numerical parametric calculation of the reduction factors becomes then:

$$
\Delta_{t o t}=\Delta_{1}+\Delta_{2}+\Delta_{3}=\frac{h}{300}+5 \mathrm{~mm}+1 \mathrm{~mm}
$$

\subsection{Development of a buckling curve}

Based on the defined initial imperfection, numerical simulations with the non-linear FE model have been performed. The range of parameters within which the simulations were carried out, are shown in Table 4. All parameters have been chosen in order to cover a wide range of typical application of glass beams in practice.

The simulations were carried out using an incremental non-linear analysis, whereas the load carrying behaviour was monitored by recording the maximum tensile stress on the glass surface and the maximum lateral deflection as a function of the applied load. The simulations were carried out on monolithic glass and laminated glass with two and four glass layers. An initial geometrical imperfection was considered in the simulation model, whereas the shape corresponded to the first eigenform, which was scaled to have the maximum amplitude given by Eq. (15). The maximum characteristic buckling strength was identified, when the maximum tensile stress somewhere on the glass surface first exceeds the maximum glass strength. The characteristic buckling strength divided by the characteristic bending strength of the glass results in a reduction factor. With the given three characteristic glass strength values for annealed, heat strengthened and fully toughened glass, each simulation database was used generate three reduction factors. Thanks to this approach 520 data points could be generated in order to establish a design buckling curve.

All generated data points, based on the parameters in Table 4, are displayed as reduction factors in the diagram in Fig. 16. The data points seem to be randomly distributed above a lower boundary line. A correlation 
Table 4 Parametric numerical simulations

\begin{tabular}{llll}
\hline Parameter & Monolithic glass & Laminated glass (2 glass layer) & Laminated glass (4 glass layer) \\
\hline Length $(\mathrm{mm})$ & $3000,6000,9000$ & $3000,6000,9000$ & 9000 \\
Height $(\mathrm{mm})$ & $150,300,450,600$ & $150,300,450$ & 600 \\
Thickness $(\mathrm{mm})$ & $6,12,19$ & $6,12,19$ & 12,19 \\
Ratio: length/height & 5 to 60 & 5 to 60 & 15 \\
Char. glass strength $f_{k}(\mathrm{MPa})$ & $45,70,120$ & $45,70,120$ & $45,70,120$ \\
Young's modulus glass $(\mathrm{MPa})$ & 70,000 & 70,000 & 70,000 \\
Interlayer thickness $(\mathrm{mm})$ & - & 1.52 & 1.52 \\
Young's modulus interlayer $(\mathrm{MPa})$ & - & $0.01,0.1,1.0,10,100$ & $0.01,0.1,1.0,10,100$ \\
Data point results for buckling curve & 100 & 400 & 20
\end{tabular}

Fig. 16 Simulated reduction factors and proposed design buckling curve

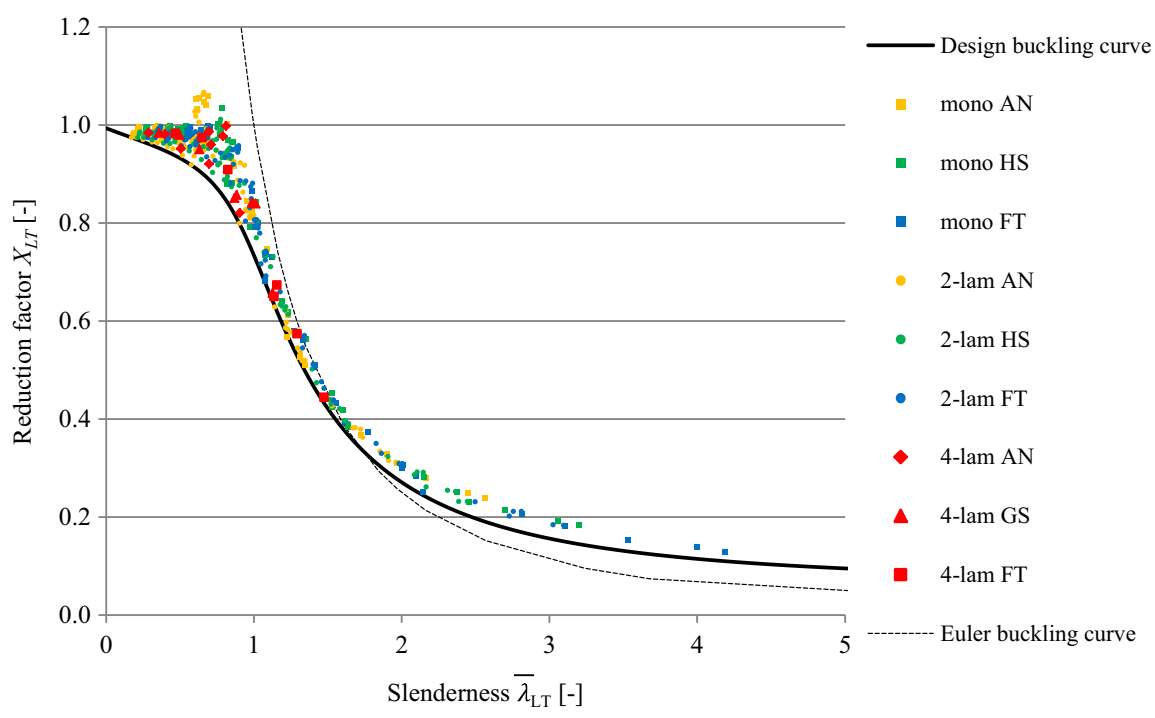

between the glass composition (AN, HS, FT), glass strength and reduction factor is not noticeable and the interlayer shear stiffness has no influence on the buckling curve. It is worth noticing that the reduction factors for slenderness values $>1.6$ are higher than the elastic critical buckling strength given by the Euler buckling curve. This effect was already observed in other research works (Luible 2004) and is due to post buckling effects. In this case the load carrying behaviour of the glass beam deviates from the typical beam theory and stiffening effects occur due to the membrane load carrying behaviour.

Based on all generated data points, a buckling curve for glass beams with a rigid lateral restraint was defined. In this context the well-known functions used in structural steel design have been adopted. The parameters of these functions have been modified and adjusted in such a way that the design curve represents a lower boundary of all generated data points. The resulting design buckling curve (Fig. 15) described with Eqs. (16) and (17) is able to provide reliable buckling reduction factors for laterally supported monolithic and laminated glass beams with rigid lateral restraints.

$$
\begin{aligned}
& \chi_{L T}=\frac{0.9}{\Phi+\sqrt{\Phi^{2}-\bar{\lambda}_{L T}^{2}}}+0.06 \leq 1.0 \\
& \Phi=0.5\left(1+0.12\left(\bar{\lambda}_{L T}-0.3\right)+\bar{\lambda}_{L T}^{2}\right)
\end{aligned}
$$

\subsection{Design concept}

The lateral torsional buckling design of a glass beam with lateral restraint then becomes straight forward with the condition: 
$M_{E d} \leq M_{R d, L T}$

whereas $M_{E d}$ is the design value of the bending moment due to the applied loads and $M_{R d, L T}$ is the design buckling resistance, which is given by

$$
M_{R d, L T}=\chi_{L T} M_{R d, y}
$$

with the design value of the bending strength around the strong axis

$$
M_{R d, y}=W_{y} \sigma_{R d}
$$

The design value of the tensile strength of glass $\sigma_{R d}$ may be taken from existing glass design codes.

\section{Summary and conclusions}

In this paper results of a recent research work on the lateral torsional buckling of laterally restraint glass beams with a stiff lateral support subjected to a continuous uniformly distributed load have been presented. The objectives of this research were to investigate the load carrying behaviour and to develop a design method for stability-critical lateral supported glass beams. Numerical simulations were carried out and compared to experimental tests on real size glass beams made of monolithic and laminated glass. Based on these studies a design concept with buckling curves and nondimensional slenderness factors was developed, an approach which is similar to existing design concepts used in steel construction. In order to establish a buckling design curve a considerable amount of non-linear numerical simulations have been performed and data points representing the reduction factors have been generated. The proposed buckling design curve represents a lower boundary line of all generated data points.

The slenderness factor is defined by the elastic critical buckling moment, which may be calculated with existing analytical approaches, numerical models or with the method shown in this paper. The approach in this paper is based on the principle of virtual work and on the assumption that the shape of the buckled glass beam corresponds to the first eigenform. A preliminary study of the shape of the eigenform was carried out in order to establish a simple analytical function. It was demonstrated that the developed analytical function is suitable to describe the shape of the buckled glass beam. The resulting elastic critical buckling moment shows a good agreement with the numerical result for monolithic glass beams.

Initial imperfections, which have a significant influence of the load bearing capacity and as a consequence also on the design buckling curve, have been discussed and established in the paper. Three relevant imperfection components have been quantified and applied for the parametric numerical simulations used for the development of the design buckling curve. Beyond the initial imperfection due to production, also imperfections due to misalignment during installation have been considered in the study.

Lateral torsional buckling tests on real size glass beams made of monolithic and laminated glass beams have been performed in order to validate the developed numerical model. For this purpose, a special test rig was developed. Especially for monolithic glass and laminated glass beams with PVB interlayer, the test results show a good agreement with the numerical simulations. However for laminated glass with EVA interlayer detailed and reliable properties of the interlayer material are required.

As shown in the research work, it is possible to establish a design concept for laterally restraint glass beams based on buckling design curves. However, in order to complete the design also the lateral support has to be verified and it has to be checked that the glass fixing is able to transfer the occurring lateral forces. A suitable lateral support is necessary to hold the glass fin in place and to avoid a premature failure of the glass fixing. A comprehensive study of these reaction support forces on the fixing points was not subject of this research work and needs to be investigated in the next stage. Preliminary studies with the developed numerical models demonstrated that the required support forces are high and that the load bearing capacity of typical structural silicon joints are not sufficient.

Conflict of interest On behalf of all authors, the corresponding author states that there is no conflict of interest.

\section{References}

Amadio, C., Bedon, C.: Buckling of laminated glass elements in out-of-plane bending. Eng. Struct. 32(11), 3780-3788 (2010)

ANSYS, A.: Academic research. Release 15, 1 (2014)

Bedon, C., Belis, J., Amadio, C.: Structural assessment and lateral-torsional buckling design of glass beams restrained by continous sealant joints. Eng Struct 102, 214-229 (2015) 
Bedon, C., Belis, J., Luible, A.: Assessment of existing analytical models for the lateral torsional buckling analysis of PVB an SG laminated glass beams via viscoelastic simulations and experiments. Eng. Struct. 60, 52-67 (2014)

Belis, J.: Kipsterkte van monolithische en gelamineerde glazen liggers. Ghent University, Ghent (2005)

Belis, J., Bedon, C., Louter, C., Amadio, C., van Impe, R.: Experimental an analytical assessment of lateral trosional buckling of laminated glass beams. Eng. Struct. 51, 295-305 (2013)

Belis, J., Luible, A., Mocibob, D., Vandenbroek, M.: On the size and shape of initial out-of-plane curvatures in structural glass components. Constr. Build. Mater. 25(5), 2700-2712 (2011)

Challamel, N., Grihammar, U.A.: Lateral-torsional buckling of vertically layered compostie beams with interlayer slip under uniform moment. Eng. Struct. 34, 505-513 (2012)

Foraboschi, P.: Analytical solution of two-layer beam taking into account nonlinear interlayer slip. J. Eng. Mech. 135, 11291146 (2009)

Gallery, S. P.: (n.d.). Steve's Photo Gallery. Retrieved 12 2015, from Steve's Photo Gallery: http://www.stevesgallery.net/ displayimage.php?album $=$ search $\&$ cat $=0 \&$ pos $=24,(2015)$
Haldimann, M., Luible, A., \& Overend, M.: Structural Use of Glass (Bd. Structural Engineering Document SED). Zürich: International Association for Bridge and Structural Engineering IABSE, ISBN 978-3-85748-119-2, (2008)

Holberndt, T.: Entwicklung eines Bemessungskonzeptes für den Nachweis von stabilitätsgefährdeten Glasträgern unter Biegebeanspruchung. Frauenhofer IRB Verlag, Stuttgart (2006)

Kasper, R.: Tragverhalten von Glasträgern. Shaker Verlag, RWTH Aachen (2005)

Luible, A.: Stabilität von Tragelementen aus Glas. Lausanne, (2004)

Schärer, D.: Beitrag zum Kippen mit gebundener Drehachse. Lucerne University of Applied Science and Arts, Horw (2015)

Stamm, K., Witte, H.: Sandwichkonstruktionen-Berechnung, Fertigung, Ausführung. Springer, Wien (1974) 